\title{
A Mobile-Assisted Learning Application of Mother Tongue for Grade 3
}

\author{
Karl Vincent C. Carreon \\ San Carlos College \\ Capataan, San Carlos City \\ Pangasinan, Philippines
}

\author{
Jessa Joy I. Mejia \\ San Carlos College \\ Cobol, San Carlos City \\ Pangasinan, Philippines
}

Hanzrick G. Palaganas
San Carlos College
Matagdem, San Carlos City
Pangasinan, Philippines

\author{
Charry Ann Joy B. Padlan \\ San Carlos College \\ Caingal, San Carlos City \\ Pangasinan, Philippines
}

\begin{abstract}
Department of Education, Philippines stated that starting school year (SY 2012-2013) the Mother Tongue-BasedMultilingual Education (MTB-MLE) must be implemented in public schools especially in Kindergarten, Grades 1, 2 and 3 as the part of K-12 Basic Education Program. In this generation, mobile application is rapidly growing in importance and can be used in different purposes and it is widely used in education. Students are more driven towards using mobile application for various purpose. Every mobile application has a unique feature which offers its own set of services.

This study proposes A Mobile-Assisted Learning Application of Mother Tongue for Grade 3. This mobile application adopted the content of the mother tongue books and curriculum guide in 3rd grading period that will act as supplement material in Bolosan-Caingal Elementary School for Grade 3. It is interactive and has a feature such as dictionary, flashcards, lesson and quiz. This feature will help the pupils to widen their vocabulary in mother tongue, and enhance their skills in pronouncing pangasinense term. Thus, it also has a quiz to test their knowledge. This mobile application is an android based.
\end{abstract}

\section{General Terms}

Mother Tongue, mobile assisted learning application, grade 3 mother tongue, pangasinan languag

\section{Keywords}

Keywords are your own designated keywords which can be used for easy location of the manuscript using any search engines.

\section{INTRODUCTION}

According to DepEd, starting school year (SY 2012-2013) the Mother Tongue-Based-Multilingual Education (MTB-MLE) will be implemented in public schools especially in Kindergarten, Grades 1, 2 and 3 as part of K-12 Basic Education Program. There are twelve (12) major dialects used in the Philippines. These are Tagalog, Pangasinense, Kapampangan, Ilokano, Bikolano, Cebuano, Hiligaynon, Waray, Tausug, Maguindanao, Maranao and Chabacano. Yet, there is not enough resources and materials like books that can be found or bought to learn these major dialects..

\section{RELATED LITERATURE}

There are 8 major languages or Lingua Franca recommended to be taught in the provinces. These are Tagalog, Pangasinense, Kapampangan, Ilokano, Bikolano, Cebuano, Hiligaynon, Waray, Tausug, Maguindanao, Maranao and Chabacano. Valerio, Ma Theresa B. ${ }^{1}$ says that many of the grade school pupils in the Philippines do not know how to speak their own mother tongue language so the Department of Education implemented the Mother Tongue BasedMultilingual Education (MTB-MLE) since 2012 under the K to 12 curriculums.

According to Espino (Governor in Pangasinan), at present time, aside from teaching Pangasinense as language, teacher is also teaching Ilokano in some towns in the province populated and dominated by the Ilocanos. The governors' aim is to save the Pangasinan language from dying or from being forgotten by the next generations of Pangasinenses. The dialect of Pangasinan is Pangasinense not pangalatok, not pangalatot, pangalatik, pangalatit and pangalato. It is very said that even some Pangasinenses call themselves with these words. Some journalists or news reporters use Pangalatok. This misconception is due to the fact that Pangasinense was not being used. Therefore, with the help of this application, Pangasinense will be made known to others especially those who are not natives of Pangasinan.

However, there is a scarcity of teaching materials related to teaching these dialects which poses as one of the challenges in the delivery of mother tongue. This problem was stated in the study of Cabansag, John N., et.al. ${ }^{2}$ His study reveals that some major problems encountered by the teachers are difficulties in translating the major dialects and lack of instructional materials.

Findings in the study of Cruz, Nora $\mathrm{T}^{3}$ revealed that Grade I pupils in public elementary schools in Pangasinan attains average percentage level performance in the mother tongue as a subject, particularly in areas that target the vocabulary and concept development, grammar analysis, and reading comprehension.

Lartec et.al. ${ }^{4}$ said that aside from lack of teaching resources and materials like books, hitch encountered by the teachers in implementing mother tongue-based instruction include lack of vocabulary and lack of teacher-training.

Costley, Kevin C. ${ }^{5}$ presented a paper on how the technology becomes more vital to students and teachers. In his study, he found out that teachers are having a hard time in teaching the 
pupils because of lack of teaching resources and materials like books.

We are positive about the development of the mobile application that would help teach students and teachers alike on the local dialect. The mobile application would be effective and helpful in teacher, parents, and pupils because this mobile application is easy to use and easy to understand. Using this mobile application, student could learn their local dialect and enhance their pronunciation skills easily. It will help teachers lessen their works in teaching the students because it would act as supplement to the usual teaching materials used and students would be familiarized with their dialect using the proposed mobile application. Moreover, parents would save money because they do not need to buy new textbooks for their children.

\section{PROJECT DESIGN AND METHODOLOGY}

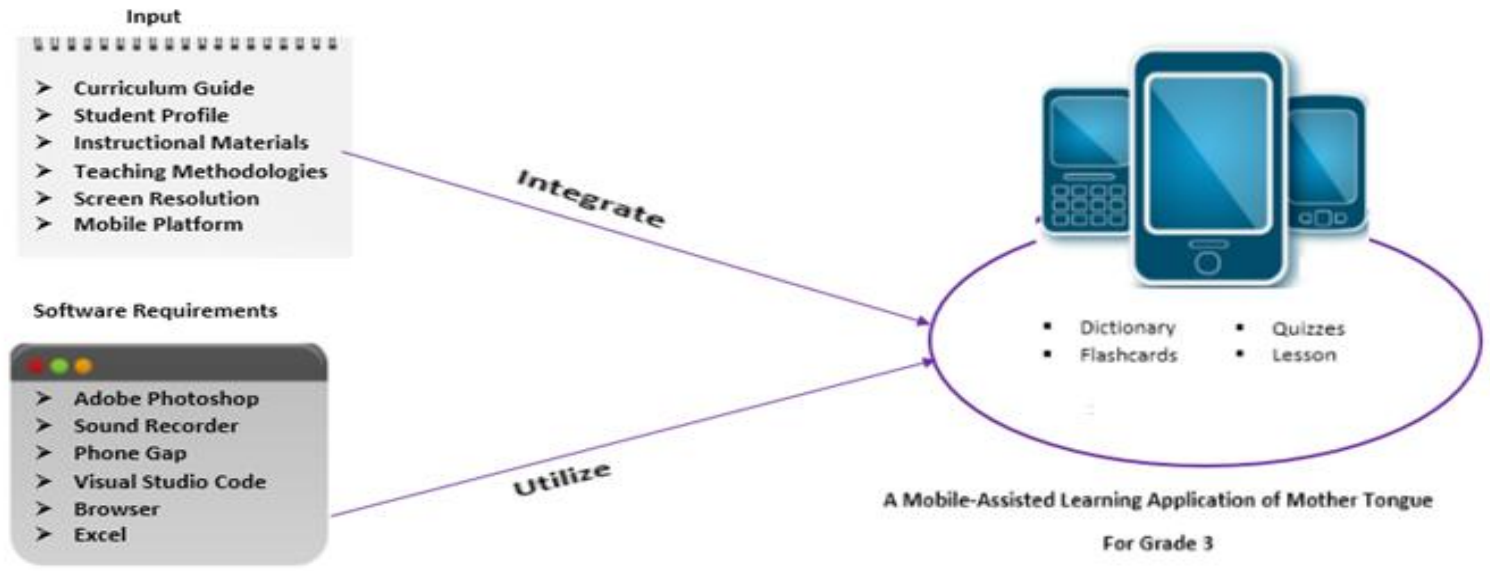

Fig 1: Operational Framework for the Proposed Project

We prepared an operational framework that served as the foundation of the study shown in figure 1 .

In order to create a mobile application, we need to gather all the data and requirements needed for the proposed study. First, we need to know the situation of the Grade 3 of Bolosan-Caingal Elementary School in their Mother Tongue Language performance. We used the DepEd's Curriculum as their reference for the content of the proposed mobile application. The current instructional materials that is being utilized by Bolosan-Caingal Elementary School, obtained as a content of proposed application. We used the teaching methodology that is used by the teachers to support the learning of students with the methodologies for a successful mobile learning application.

We chose the modified waterfall model as a methodology in order to develop the mobile application and to solve the identified problems of the proposed study. This incorporates different development phases that happen in the life of project starting right from the project plan is made.

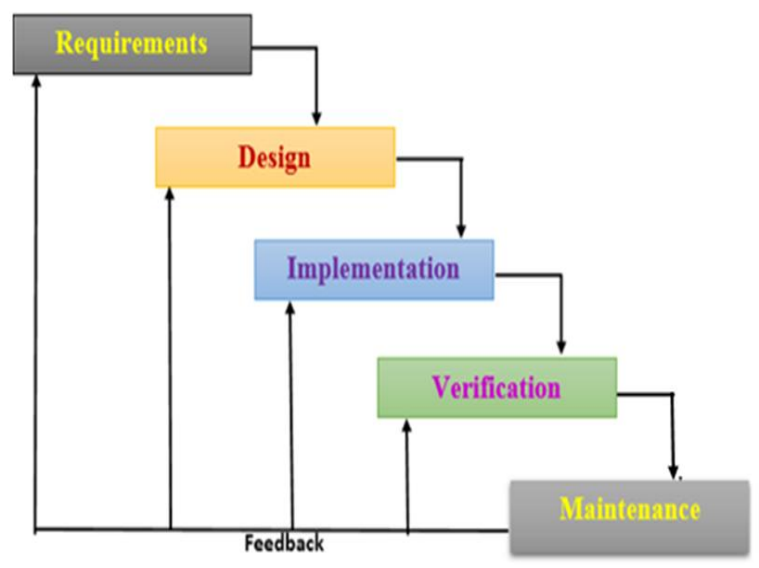

Fig 2: Modified Waterfall Model

\section{PROJECT DESIGN AND ANALYSIS OF DATA}

This chapter presents all the results of data analysis, summary about the interpretation of results from the conducted survey. This tackles about the information of Grade 3 advisers and pupils, the chosen programming language and the needed software and hardware tools to be used in the development of mobile application and the Software Development Life Cycle (SDLC) phases that served as a guide in the development process of the mobile application. 


\subsection{Software Development Life Cycle (SDLC)}

Software Development Life Cycle (SDLC) is a step-by-step process that describes how to design and maintain the specific software requirements that is needed in developing the mobile application. The purpose of the Software Development Life Cycle (SDLC) is to develop a good quality and effectiveness of a mobile application and to ensure that the functional and non-functional requirements, goals and objectives are met.

\subsection{Requirements Analysis}

In this stage, we conducted an interview to collect and analyze all the needed information in Bolosan-Caingal Elementary School regarding the subject mother tongue in order to provide the solution. We interviewed the principal of Bolosan-Caingal Elementary School as well as the teachers of Grade 3. We gathered the school profile, the pupil's performance and grades on mother tongue subject, existing resources materials and the curriculum guide.

\subsection{Design}

We start to create design of the proposed mobile application after identifying all the objectives of the project. In this phase the user interface and the application logic were designed. In order to describe and represent the user's interface with the application.

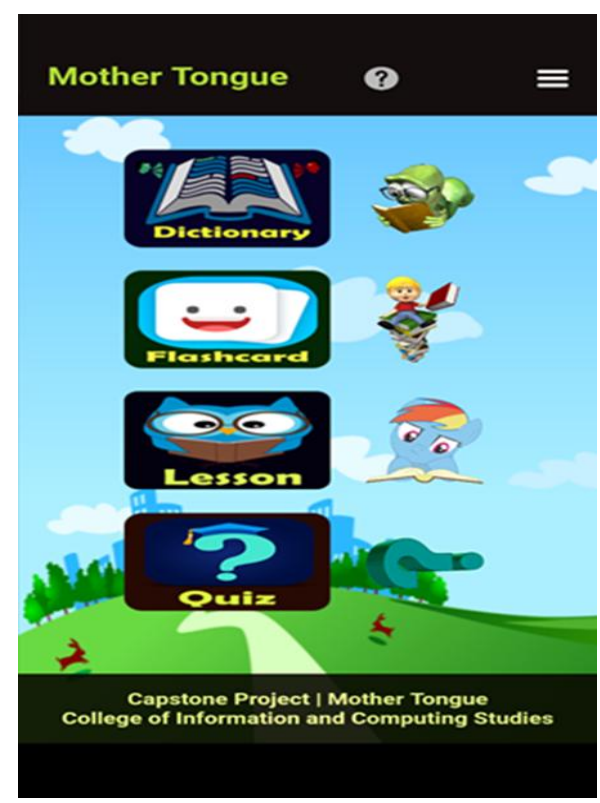

Fig 3: Mobile Application Home Screen

Figure 3 shows the home screen. The header of the home screen contains the title of the mobile application, help button and the menu bar. The title "Mother Tongue" is clickable that directs to the welcome screen. There are four clickable buttons, which includes dictionary, flashcard, lesson, and quiz. Also, the footer of this welcome screen, which is "Capstone Project", the name of the mobile application "Mother Tongue", and the name of the department "College of Information and Computing Studies".

\subsection{Implementation}

Implementation is the action that must be followed in order that something actually happened. It incorporates the actual building of the software as set out of the design phase. It deals with the issues of quality, performance, baselines and the end deliverable are simply the item.

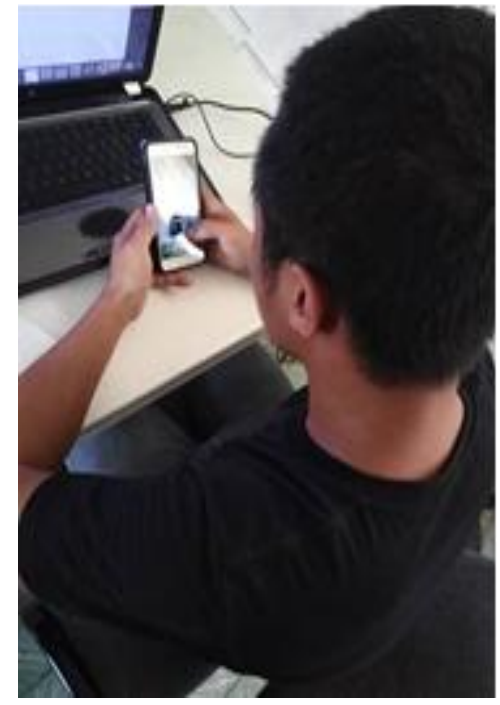

Fig 4: Proponent Testing the Application

Figure 4 shows that we need make some test regarding all the needed requirements and specifications in developing the mobile application wherein stage were analyzed. To make sure that the mobile application will perform well, we test it first by installing the mobile application in their android phone. While using it, the proponent does not encounter any problem, the mobile application performs well.

\subsection{Verification}

This phase is about evaluating the mobile application. If it complies with a regulation, requirements and specification. It also deals in verifying the mobile application to ensure that the application meets the needed design and specification. Furthermore, verification includes performing test in an actual mobile application.

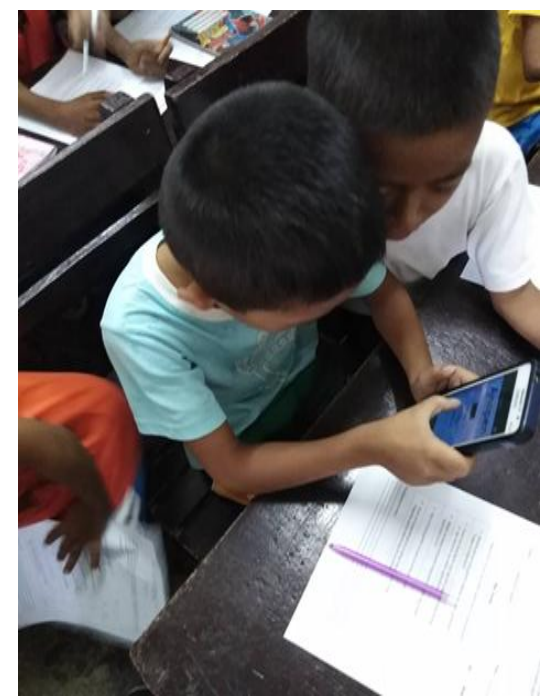

Fig 5: Pupils answering survey

After we introduced the mobile application, we gave a survey form to the pupils to find out if the application is useful and met their standards. In figure 20 shows the pupils answering the survey form that will serve as a proof that the mobile application is excellent. 
Table 1. Experimental and Comparison Groups results.

\begin{tabular}{|c|c|c|c|c|c|}
\hline & & Recitation & Homework & Quizzes & Total \\
\hline \multirow{3}{*}{$\begin{array}{l}\text { Grade } \\
3 \text { ND }\end{array}$} & Boys & 10 & 10 & 10 & 30 \\
\hline & Girls & 20 & 20 & 20 & 60 \\
\hline & \multicolumn{4}{|c|}{ Percentage } & $90 \%$ \\
\hline \multirow{3}{*}{$\begin{array}{l}\text { Grade } \\
3 \mathrm{MC}\end{array}$} & Boys & 10 & 10 & 10 & 30 \\
\hline & Girls & 20 & 10 & 20 & 50 \\
\hline & \multicolumn{4}{|c|}{ Percentage } & $80 \%$ \\
\hline
\end{tabular}

\subsection{Deployment}

Deployment is a stage wherein all the assumption of mobile application is turned into practice. After all the testing, activities and specific requirements of the application were done, the mobile application will move to deployment phase. We determined that it is now ready for deployment. The objective of the study is to meet the functionality, usability and effectiveness from the user's point of view.

\subsection{Maintenance}

The maintenance phase occurs after the application is in full operation. Maintenance of application can include system upgrades, repairs and fixes of the system if it breaks. During the maintenance phase errors or defects may exist, which would require repair during additional testing of the application. Monitoring the performance of the application is also included during maintenance phase.

\section{CONCLUSION AND RECOMMENDATION}

\subsection{Conclusion}

The problem encountered by the teachers are, the pupils are lazy to bring their books, some of the pangasinense words are not familiar to them, hard to pronounce and deficient instructional and resource materials.Based on our observation the affectivity of the proposed mobile application is $90 \%$ for the boys and girls of grade $3 \mathrm{ND}$ or the experimental group develop their reading and speaking skills utilizing the mobile application. While the comparison group is $80 \%$ of them develop without mobile application. Which is lower than the experimental group the mobile application was effective based on the scores of the experimental group.

\subsection{Recommendation}

We recommend that the mobile application must be used as a supplement material of pupils in their mother tongue subject. This application would educate the pupils because the application was adopted in the mother tongue curriculum guide and books. In addition, the parents should have a meeting on how to use the mobile application and they should provide mobile phones and assist their children because they are only grade 3 . We are looking for the improvement of the mobile application. They recommend that the school should continue developing the mobile application by adding some features and functionalities to ensure that the applications is personalized to individual learner's level of knowledge.

\section{REFERENCES}

[1] Valerio, Ma Theresa B. 2015. "Current Perspective on Mother-Tongue Based Instruction in the Newly Implemented K to 12 Curriculum of the Philippines."

[2] Cabansag John N, et.al. 2016. "The Implementation of Mother Tongue-Based Multilingual Education: Seeing It from the Stakeholders' Perspective."

[3] Cruz, Nora T., 2015. "The Implementation of the Mother Tongue-Based Multilingual Education in Grade 1 in the Public Elementary Schools in Pangasinan."

[4] Lartec et.al. 2014. "Strategies and Problems Encountered by Teachers in Implementing Mother Tongue - Based Instruction in a Multilingual Classroom."

[5] Costley, Kevin C. 2014. "The Positive Effects of Technology on Teaching and Student Learning." 